\title{
Primary pulmonary lymphoepithelioma-like carcinoma in a 12-year-old African child
}

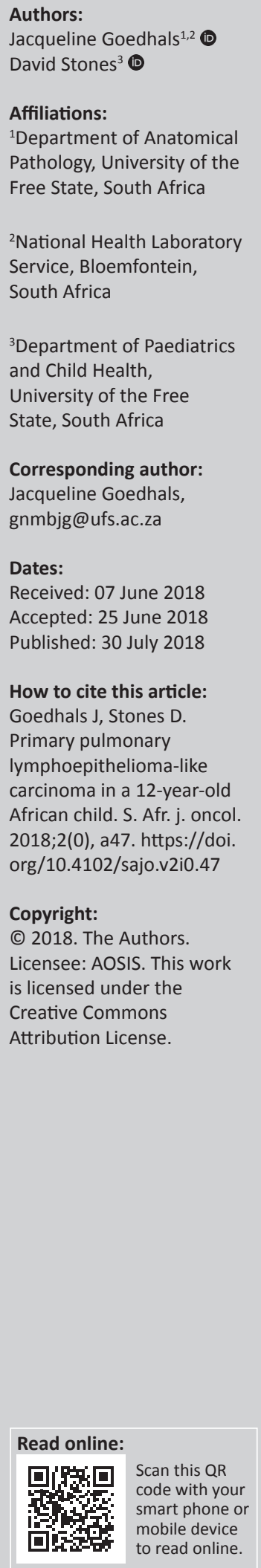

Pulmonary lymphoepithelioma-like carcinoma is a rare malignant tumour predominantly occurring in Asian patients. It has identical histological features to nasopharyngeal carcinoma. To date, Epstein-Barr virus (EBV) in pulmonary lymphoepithelioma-like carcinoma has been limited to the Asian population. This manuscript presents an unusual case in a 12-year-old African boy in which the tumour tested positive for EBV.

\section{Introduction}

Lymphoepithelioma-like carcinoma (LELC) can occur in a number of sites including the thymus, salivary gland, stomach, skin, uterine cervix, tonsil, oral cavity, trachea, larynx, urinary bladder and vagina. ${ }^{1}$ Primary pulmonary LELC was first described by Bégin et al. ${ }^{2}$ in 1987 and is a distinct subtype of non-small cell lung cancer. ${ }^{3}$ It occurs predominantly in Asian patients, and only four cases of pulmonary LELC have been documented in black patients. ${ }^{4}$ Although LELC tends to affect younger, non-smoking patients, only isolated cases occurring in children have been published to date.

We present an unusual case of primary pulmonary LELC in a 12-year-old African child in which the tumour tested positive for Epstein-Barr virus (EBV).

\section{Case}

A 12-year-old HIV-negative African boy presented with a history of coughing and dyspnoea for a period of 6 months. He was placed on treatment for tuberculosis without microbiological confirmation and his symptoms became more severe over the next month. He experienced difficulty breathing and asthma medications were prescribed. Regardless, his condition continued to deteriorate. On examination at admission, he had clubbing of his fingers and severe respiratory distress with subcostal and intercostal retraction and global wheezing. His trachea was displaced to the left, and the right side of his chest appeared more prominent and hyperinflated. The left chest was dull to percussion. He had decreased breath sounds and air entry of the left hemithorax. His respiratory rate was 28 breaths per minute, with a functional oxygen saturation $\left(\mathrm{SpO}_{2}\right)$ of $81 \%$.

On an X-ray of the chest, we observed a hyperinflated right lung with the mediastinum, trachea and heart all displaced into the left hemithorax (Figure 1a). A chest computed tomography (CT) scan showed a left endobronchial mass that measured $58 \mathrm{~mm} \times 49 \mathrm{~mm} \times 55 \mathrm{~mm}$ extending into the trachea, with collapse of the left lung (Figure 1b). A bronchoscopy was performed and the mass was biopsied.

Histology showed nests and sheets of pleomorphic tumour cells with prominent nucleoli and a syncytial arrangement. A marked lymphocytic infiltrate was also present (Figure 1d). Immunohistochemical stains for AE1/AE3, CK5/6 and p63 were positive in the epithelial cells, while a leukocyte common antigen (LCA) was positive in the lymphocytes. A negative placental alkaline phosphatase (PLAP) stain excluded a germ cell tumour and negative chromogranin and synaptophysin stains excluded a neuroendocrine tumour. In addition, stains for CK7, CK20, TTF1 and napsin A were negative. Epstein-Barr encoding region (EBER) in situ hybridisation (EBERISH) was positive (Figure 1e).

A differential diagnosis of LELC of the lung or metastatic nasopharyngeal carcinoma was made. On further investigation, no nasopharyngeal mass was evident and, consequently, the final diagnosis was that of a primary pulmonary LELC. He was given six cycles of chemotherapy that included cisplatinum, 5-fluorouracil and leucovorin. He also received 6 weeks of irradiation with a total dose of 5400 cGy. A follow-up CT scan (Figure 1c) 6 months after completion of treatment showed a small $17 \mathrm{~mm} \times 14 \mathrm{~mm}$ mass adjacent to the left main 

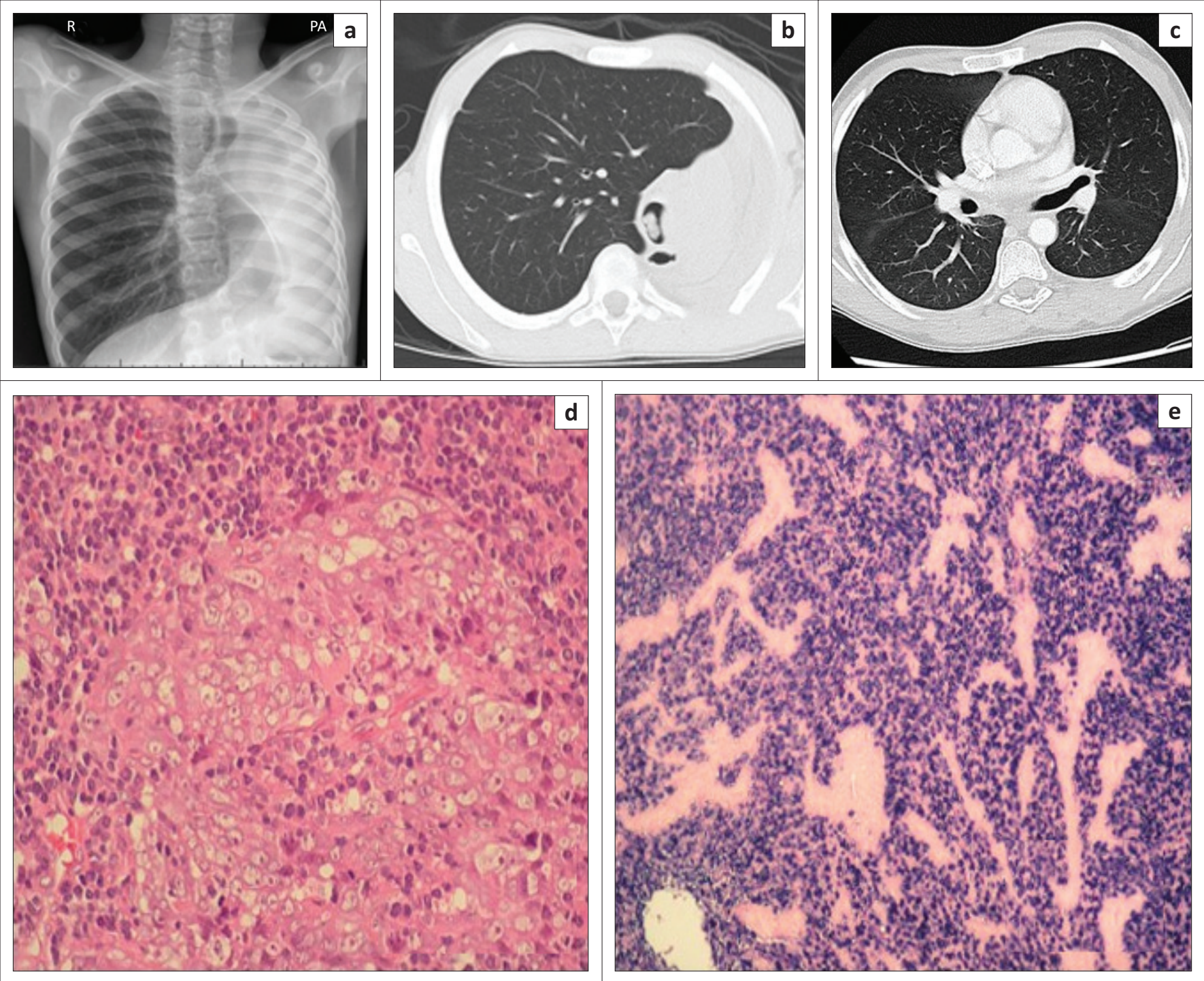

EBER, Epstein-Barr encoding region, ISH, in situ hybridisation.

FIGURE 1: (a) Chest x-ray at presentation shows a collapsed left lung with mediastinal, tracheal and cardiac displacement, (b) CT scan at presentation demonstrates marked hyperinflation of the right lung with a collapsed left lung and a mass in the left main bronchus, (c) CT scan 6 months post-treatment completion shows normal lungs and no evidence of the bronchial mass, (d) Histological features of the tumour. Sheets of pleomorphic tumour cells with a syncytial arrangement infiltrated and surrounded by numerous lymphocytes, (e) EBER-ISH with strong positivity.

bronchus, which was consistent with post-therapy fibrosis, and the lung collapse had resolved. When seen at his 12-month follow-up, the patient was alive and disease-free.

\section{Ethical considerations}

Ethical approval to report the case was obtained from the institutional Ethics Committee (reference number HSREC 176/2017). The child's mother provided written consent to publish the findings and images obtained during work-up of this case.

\section{Discussion}

Pulmonary LELC is a rare tumour most commonly occurring in Asian patients. Patients tend to be younger than those with other types of lung cancer, and there is no sex predilection. They are also more likely to present at an earlier stage. As seen in this case, the majority of patients present with a history of coughing. ${ }^{5}$ Other symptoms include haemoptysis, chest pain and weight loss. The prognosis of patients with pulmonary LELC is significantly better than those with other types of lung carcinoma. ${ }^{4,6}$ In a series of 62 patients reported by He et al. ${ }^{4}$ the median survival of patients with LELC was 107 months, in contrast to a median survival of 13 months for non-LELC patients. Han et al. ${ }^{6}$ showed a significant difference in survival for patients with stage II, III and IV disease. However, there was no significant difference in survival rates among patients with stage I disease. Tumour recurrence and necrosis have been associated with a poor prognosis. ${ }^{6}$ Patients over 65 years of age have also been found to have a significantly worse survival outcome. ${ }^{4}$

It is important to distinguish pulmonary LELC from nasopharyngeal carcinoma with metastases to the lungs, as both tumours have an identical histological appearance. Misdiagnosis will lead to incorrect staging and management. In addition, cases with a very prominent lymphoid infiltrate 
TABLE 1. Reported cases of paediatric pulmonary lymphoepithelioma-like carcinoma.

\begin{tabular}{lcllll}
\hline Author & Age (years) & Gender & Race & Presentation & Outcome \\
\hline Liang et al. ${ }^{3}$ & 9 & Female & Chinese & Not stated & Alive at 37.8 months \\
${\text { He et al. }{ }^{4}}^{\text {Curcio et al. }{ }^{9}}$ & 15 & Not stated & Not stated & Not stated & Not stated \\
${\text { Kundu et al. }{ }^{10}}$ & 8 & Female & Chinese & Clubbing of fingers and toes & Alive and disease-free at 20 months \\
Present case & 13 & Female & Indian & $\begin{array}{l}\text { Cough, intermittent fever and progressive } \\
\text { dyspnoea }\end{array}$ & $\begin{array}{l}\text { Alive and symptom-free after more than } \\
2 \text { years }\end{array}$ \\
\hline
\end{tabular}

EBER, Epstein-Barr encoding region.

could be mistaken for non-Hodgkin lymphoma, which does not require surgical intervention.,

Only tumours from the upper aero-digestive tract and thymus have been associated with EBV. This association has been limited to Asians with LELC of the salivary gland and lung. ${ }^{1,5}$ This article presents the first documented case of EBVpositive pulmonary LELC in an African patient.

Four cases of pulmonary LELC have been described in children. Curcio et al. ${ }^{9}$ reported a case in an 8-year-old girl of Chinese decent, while Kundu et al..$^{10}$ described a case of LELC in a 13-year-old girl of Indian decent. A 9-year-old Chinese girl was reported by Liang et al. ${ }^{3}$ in a case series of 52 patients, while He et al. ${ }^{4}$ found that the youngest person in their series of 62 patients was 15 years old (Table 1). One of the patients reported previously was alive without evidence of recurrence after 20 months $^{9}$ and another one after more than 2 years of follow-up. ${ }^{10}$ The 9 -year-old child reported by Liang et al. ${ }^{3}$ was alive after 37.8 months, although no further information was provided. No follow-up data were available for the 15-yearold case reported by He et al. ${ }^{4}$ In our case, the patient was a 12-year-old boy of African descent who had responded well to treatment. He was initially misdiagnosed with pulmonary tuberculosis because of the clinical history of coughing and a positive tuberculosis contact. Although pulmonary tumours are rare in children and tuberculosis is extremely common in South Africa, ${ }^{11}$ it is important to exclude the possibility of a tumour to avoid delays in treatment.

In summary, we present a rare case of EBV-positive pulmonary LELC in an African child. Metastases from a nasopharyngeal carcinoma should be excluded before making a diagnosis of pulmonary LELC.

\section{Acknowledgements}

The authors thank Dr Daleen Struwig, medical writer and editor, for the technical and editorial preparation of the manuscript.

\section{Competing interests}

The authors declare that they have no financial or personal relationships that may have inappropriately influenced them in writing this article.

\section{Authors' contributions}

J.G. was responsible for the histological investigations, provided the histology photographs and wrote the manuscript. D.S. provided the clinical information and radiological images and approved the final version of the manuscript.

\section{References}

1. lezzoni JC, Gaffey MJ, Weiss LM. The role of Epstein-Barr virus in lymphoepithelioma-like carcinomas. Am J Clin Pathol. 1995;103(3):308-315. https://doi.org/10.1093/ajcp/103.3.308

2. Bégin LR, Eskandari J, Joncas J, Panasci L. Epstein-Barr virus related lymphoepithelioma-like carcinoma of lung. J Surg Oncol. 1987;36(4):280-283. https://doi.org/10.1002/jso.2930360413

3. Liang $Y$, Wang L, Zhu $Y$, et al. Primary pulmonary lymphoepithelioma-like carcinoma: Fifty-two patients with long-term follow-up. Cancer. 2012;118(19):4748-4758. https://doi.org/10.1002/cncr.27452

4. He J, Shen J, Pan H, Huang J, Liang W, He J. Pulmonary lymphoepithelioma-like carcinoma: A surveillance, epidemiology and end results database analysis. J Thorac Dis. 2015;7(12):2330-2338. https://doi.org/10.3978/j.issn.2072-1439. 2015.12.62

5. Ho JC, Wong MP, Lam WK. Lymphoepithelioma-like carcinoma of the lung. Respirology. 2006;11(5):539-545. https://doi.org/10.1111/j.1440-1843.2006.00910.x

6. Han A, Xiong M, Gu Y, Lin SX, Xiong M. Lymphoepithelioma-like carcinoma of the lung with a better prognosis. A clinicopathologic study of 32 cases. Am 69U9-C3H8

7. Butler AE, Colby TV, Weiss L, Lombard C. Lymphoepithelioma-like carcinoma of the lung. Am J Surg Pathol. 1989;13(8):632-639. https://doi. org/10.1097/00000478-198908000-00002

8. Huang YC, Hsueh C, Ho SY, Liao CY. Lymphoepithelioma-like carcinoma of the lung: An unusual case and literature review. Case Rep Pulmonol. 2013;2013:143405. https://doi.org/10.1155/2013/143405

9. Curcio LD, Cohen JS, Grannis FW Jr, Paz IB, Chilcote R, Weiss LM. Primary lymphoepithelioma-like carcinoma of the lung in a child. Report of an EpsteinBarr virus-related neoplasm. Chest. 1997;111(1):250-251. https://doi.org/ 10.1378/chest.111.1.250

10. Kundu S, Mitra R, Majumdar A, Saha S, Misra S. Primary lymphoepithelioma-like carcinoma of the lung in a 13 year old girl. Oman Med J. 2012;27(1):e032. https:// doi.org/10.5001/0mj.2012.21.

11. World Health Organization (WHO). 2015 Global tuberculosis report [homepage on the Internet]. Geneva: WHO; 2015, p. 13-14. [cited 2018 Jan 25]. Available from: https://www.health-e.org.za/wp-content/.../10/Global-TB-Report-2015-FINAL-2.pdf 